\title{
USO TERAPÊUTICO DA FITOTERAPIA NO SISTEMA ÚNICO DE SAÚDE
}

\section{Beatriz Cunha da Paixãoํㅜ, Renata Maiana de Almeida Ferreira Oliveira ${ }^{2}$, Sthefani Sávia Dantas Guimarães ${ }^{3}$, Cristiane Queiroz Borges ${ }^{4}$ Matheus Sobral Silveira $^{5}$}

\author{
${ }^{1}$ Centro Universitário Estácio da Bahia ${ }^{2}$ Centro Universitário Estácio da Bahia \\ ${ }^{3}$ Centro Universitário Estácio da Bahia ${ }^{4}$ Centro Universitário Estácio da Bahia \\ ${ }^{5}$ Centro Universitário Estácio da Bahia
}

DOI: $10.47094 /$ ICONRES.2021/2

Introdução: Segundo o Ministério da Saúde (MS), a fitoterapia é a terapêutica caracterizada pelo uso de plantas medicinais em suas diferentes formas farmacêuticas, sem a utilização de substâncias ativas isoladas, ainda que de origem vegetal. Desta forma, considerando a biodiversidade do Brasil, e tendo o objetivo de melhorar a saúde da população, o MS vem investindo no uso da fitoterapia para o Sistema Único de Saúde (SUS). Objetivo: Verificar o uso terapêutico da fitoterapia no Sistema Único de Saúde no Brasil. Metodologia: Foi adotado revisão da literatura, consistindo na busca em banco de dados da Scientific Electronic Library Online- SCIELO, Medical Literature Analysis and Retrieval System Online - MEDLINE, Literatura Latino Americana e do Caribe em Ciências da Saúde - LILACS, Biblioteca Virtual em Saúde (BVS) e US National Library of Medicine- PUBMED, publicados no período de 2010 a 2020. A busca bibliográfica foi realizada entre os meses de setembro a dezembro de 2020 sendo utilizados 23 artigos originais. Resultados: A fitoterapia é reconhecida como um método eficaz de tratamento e cura. A evolução histórica do reconhecimento dessa prática conduziu à regulamentação de políticas de incentivo à pesquisa. Observa-se o crescimento do número de programas de fitoterapia no SUS, contudo, para a introdução desta prática como terapêutica se faz necessário planejar e executar atividades voltadas para a educação em saúde, valorizando também os aspectos culturais envolvidos no seu uso. Conclusão: De acordo com a revisão, foi perceptível que o conhecimento da fitoterapia necessita ser difundido entre os profissionais do sistema de saúde, que muitas vezes não se sentem seguros para sua prescrição. Aponta-se que a Política Nacional possibilitou o aumento expressivo do número de programas voltados para a expansão da fitoterapia, entretanto, é preciso a inserção de fomentos para aprimorar a aplicabilidade.

Palavras-chave: Brasil. Plantas medicinais. Programas.

Área Temática: Saúde Coletiva 